\title{
Observations of oxidation products above a forest imply biogenic emissions of very reactive compounds
}

\author{
R. Holzinger ${ }^{1}$, A. Lee ${ }^{1}$, K. T. Paw $U^{2}$, and A. H. Goldstein ${ }^{1}$ \\ ${ }^{1}$ Department of Environmental Science, Policy, and Management (ESPM), Division of Ecosystem Sciences, University of \\ California, Berkeley, California, 94720-3110, USA \\ ${ }^{2}$ Atmospheric Science Program, Department of Land, Air, and Water Resources, University of California, Davis, California, \\ 95616-8717, USA
}

Received: 20 July 2004 - Published in Atmos. Chem. Phys. Discuss.: 15 September 2004

Revised: 3 December 2004 - Accepted: 6 January 2005 - Published: 20 January 2005

\begin{abstract}
Vertical gradients of mixing ratios of volatile organic compounds have been measured in a Ponderosa pine forest in Central California $\left(38.90^{\circ} \mathrm{N}, 120.63^{\circ} \mathrm{W}, 1315 \mathrm{~m}\right)$. These measurements reveal large quantities of previously unreported oxidation products of short lived biogenic precursors. The emission of biogenic precursors must be in the range of $13-66 \mu \mathrm{mol} \mathrm{m}^{-2} \mathrm{~h}^{-1}$ to produce the observed oxidation products. That is $6-30$ times the emissions of total monoterpenes observed above the forest canopy on a molar basis. These reactive precursors constitute a large fraction of biogenic emissions at this site, and are not included in current emission inventories. When oxidized by ozone they should efficiently produce secondary aerosol and hydroxyl radicals.
\end{abstract}

\section{Introduction}

Biogenic hydrocarbon emissions are the dominant source of reduced organic gases to the atmosphere, even larger than anthropogenic pollution and biomass burning. Naturally these emissions play important roles in global, regional, and local atmospheric chemistry. In this paper we present evidence that a significant fraction of biogenic volatile organic compounds (VOC) emitted by a coniferous forest react within the canopy on time scales of a minute or less. Our results refer to a class of very reactive biogenic volatile organic compounds (VR-BVOC) that have not been accounted for in current biogenic emission inventories or in atmospheric chemistry models. Once airborne VR-BVOCs are too reactive to escape the forest canopy, however, their effect is important for several reasons: (i) their short lifetime makes them a previously unaccounted sink for reactive species like $\mathrm{O}_{3}$ and possibly a source of $\mathrm{OH}$; (ii) their oxidation products may be relatively stable and thus be transported, affecting atmospheric chem-

Correspondence to: R. Holzinger

(holzing@ nature.berkeley.edu) istry on much larger scales; (iii) VR-BVOC emission and/or their oxidation products are likely to partition into particles and contribute to secondary organic aerosol formation and growth.

The production and emission of VR-BVOCs by plants may have evolved in response to the atmospheric environment. Scavenging atmospheric oxidants such as $\mathrm{O}_{3}$ that could otherwise damage plant tissues is a potential defense mechanism for the plant. Aerosol formation and growth increases diffuse radiation and therefore increases the light use efficiency of plants within the forest canopy. On a larger scale secondary organic aerosol formation and growth can impact the radiation balance, cloud formation and precipitation, and thus have feedbacks to ecosystems on a global scale.

Kurpius and Goldstein (2003) showed that the observed canopy scale ozone flux at this site can not be explained by stomatal uptake and dry deposition alone; half of the measured flux in summer must be due to an additional sink, which was presumed to be chemical reaction with biogenically emitted compounds. Fluxes of total monoterpenes measured above the forest are only about $10 \%$ of the chemical ozone sink on molar basis; however, both the chemical ozone sink and the monoterpene emission exhibit the same temperature dependence. Forest thinning in spring 2000 caused measured terpene flux to increase by a factor of 10 (Schade and Goldstein, 2003); the chemical loss of ozone simultaneously increased by a similar factor (Goldstein et al., 2004). This set of observations strongly suggests that chemical ozone loss is linked with biogenic emission of VRBVOCs, most likely terpenoid compounds. As will be discussed below, the postulated compounds must have a very short lifetime (few minutes or less) and react with ozone (most likely also with $\mathrm{OH}$ ) before leaving the forest canopy. Terpenoid compounds with such short lifetimes with respect to ozone mixing ratio have indeed been observed at our site (Goldstein et al. 2004).

(C) 2005 Author(s). This work is licensed under a Creative Commons License. 


\section{Experimental}

Ecosystem scale fluxes of gases including $\mathrm{CO}_{2}, \mathrm{O}_{3}$ and VOCs have been measured for several years at the same site (Blodgett Forest) on the western slope of the Sierra Nevada, California $\left(38.90^{\circ} \mathrm{N}, 120.63^{\circ} \mathrm{W}, 1315 \mathrm{~m}\right.$ elevation; Goldstein et al., 2000; Lamanna and Goldstein, 1999; Schade and Goldstein, 2001). The plantation is located $75 \mathrm{~km}$ downwind (northeast) of Sacramento and receives anthropogenically impacted air masses rising from the valley below during the day (Bauer et al., 2000). Anthropogenic pollutants, such as carbon monoxide, oxides of nitrogen, and many volatile organic compounds we measure, are transported to the site from sources that are typically 5-6h transport time away; therefore their mixing ratios are lower before noon and rise in the afternoon coinciding with the arrival of polluted air from the Sacramento region. This has been discussed in detail in several papers reporting observations from Blodgett Forest (e.g. Lamanna and Goldstein, 1999; Dillon et al., 2002). Ozone concentrations largely follow the diurnal pattern of transported compounds. Summer mixing ratios typically were $50 \mathrm{nmol} / \mathrm{mol}$ before noon and $100 \mathrm{nmol} / \mathrm{mol}$ in the afternoon. At night the wind usually shifts towards the west and air masses descend from the sparsely populated Sierra Nevada to the site. The site was planted with Pinus ponderosa L. in 1990, interspersed with a few individuals of Douglas fir, white fir, California black oak, and incense cedar. Average tree height was 4.8 (median) in 2003; the canopy height was $6.4 \mathrm{~m}$, a height exceeded by $20 \%$ of the trees. The understory was composed primarily of manzanita (Arctostaphylos spp.) and whitethorn (Ceonothus cordulatus) shrubs.

Measurements were made at the Blodgett Forest site for 47 days from 25 June-23 September 2003. VOC mixing ratios were measured in situ by Proton-Transfer-Reaction Mass Spectrometry (PTR-MS), which has been described elsewhere in detail (Lindinger et al., 1998). During each hour air was sampled through 6 individual gas inlets each of which were protected by a Teflon filter (PFA holder, PTFE membrane, pore size $2 \mu \mathrm{m}$ ). One inlet was used to sample air at $12.5 \mathrm{~m}$ from 0 to $30 \mathrm{~min}$ for eddy-covariance flux measurements of total monoterpenes; for 9 days (12-23 September 2003) fluxes of 2-Methyl-3-buten-2-ol (MBO) were measured in addition. A sample flow of $10 \mathrm{~L} / \mathrm{min}$ was maintained by a mass flow controller (MKS Instruments) and the Teflon filter was significantly blackened due to dust and particles when replaced typically every other week. Five inlets were used to sample vertical gradients at height-levels within $(1.1 \mathrm{~m}, 3.1 \mathrm{~m}, 4.9 \mathrm{~m})$ and above $(8.75 \mathrm{~m}, 12.5 \mathrm{~m})$ the forest canopy sequentially for $6 \mathrm{~min}$ each during the second $30 \mathrm{~min}$ of each hour (Fig. 1). The 5 gradient inlets were identically designed; each consisted of $30 \mathrm{~m}$ PFA tubing (ID $\sim 4 \mathrm{~mm}$ ) protected by a Teflon filter and a sample flow of $1 \mathrm{~L} / \mathrm{min}$ was maintained at all times through each sample tube. The Teflon filters on the gradient inlets were replaced every 3-6 weeks.

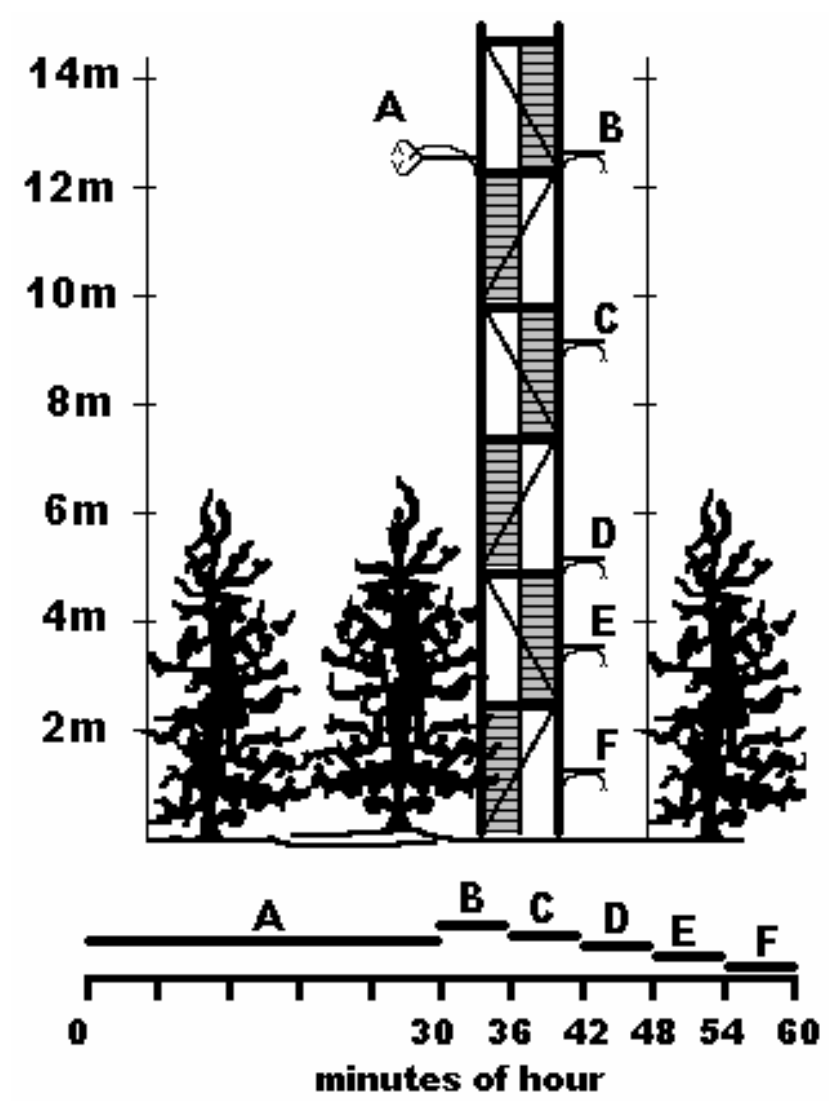

Fig. 1. VOC-gradients were measured during the second $30 \mathrm{~min}$ of each hour. The PTR-MS sampled from 5 individual inlets (B-F) positioned at $1.1,3.1,4.9,8.75$, and $12.5 \mathrm{~m}$ above ground. Canopy height was $6.4 \mathrm{~m}$.

Usually no blackening was observed on used filters, and we did not see changes in any signal of the reported compounds after changing the filters. In September 2003 we divided the sample time between the 2 inlets at $12.5 \mathrm{~m}$ (one gradient inlet and the eddy-covariance flux inlet) and for these two inlets at the same height level with different flow rates, and thus different particulate loading on the filters, none of the reported compounds showed differences in concentration.

The instrumental background levels were measured by directing the sample flow through a catalytic converter during minutes 53-55 of each hour. The converter consisted of a stainless steel tube filled with Platinum-coated quartz wool (Shimadzu) heated to $350^{\circ} \mathrm{C}$, which efficiently removed the VOCs from the sample. The catalytic converter did not remove water vapor from the sample, which is important because the background impurities may depend on the humidity of the sampled air.

The gradient measurements were made at a frequency of approximately one scan per minute. Measuring in the selected ion mode we chose about 50 masses from 18-220 amu (atomic mass unit) with a dwell time on each mass of $1 \mathrm{~s}$. 
Table 1. Composition of compounds measured at the Blodgett Forest site in summer 2003.

\begin{tabular}{|c|c|c|c|c|c|}
\hline Name & $\begin{array}{l}\text { monitored } \\
\text { mass/charge }\end{array}$ & $\begin{array}{l}\text { Typical mixing ratio } \\
(\mathrm{nmol} / \mathrm{mol})\end{array}$ & accuracy & precision & monitored ions \\
\hline Methanol & 33 & 9 & $\pm 20 \%$ & $<5 \%$ & $\mathrm{CH}_{3} \mathrm{OHH}^{+}$ \\
\hline acetaldehyde & 45 & 2.5 & $\pm 20 \%$ & $<5 \%$ & $\mathrm{C}_{2} \mathrm{H}_{4} \mathrm{OH}^{+}$ \\
\hline acetone & 59 & 5 & $\pm 20 \%$ & $<5 \%$ & $\mathrm{C}_{3} \mathrm{H}_{6} \mathrm{OH}^{+}$ \\
\hline $\mathrm{MBO}^{a}$ & 87 & 8 & $\pm 20 \%$ & $<5 \%$ & $\mathrm{C}_{5} \mathrm{H}_{9} \mathrm{OHH}^{+}$ \\
\hline monoterpenes $^{b}$ & 81,137 & 0.5 & $\pm 20 \%$ & $<5 \%$ & $\mathrm{C}_{10} \mathrm{H}_{16} \mathrm{H}^{+}, \mathrm{C}_{6} \mathrm{H}_{9}^{+}$ \\
\hline nopinone $^{c}$ & 139 & 0.12 & $\pm 30 \%$ & $<15 \%$ & $\mathrm{C}_{9} \mathrm{H}_{14} \mathrm{OH}^{+}$ \\
\hline pinonaldehyde $^{c}$ & 151 & 0.02 & $+80 \%-30 \%$ & $<30 \%$ & $\mathrm{C}_{10} \mathrm{H}_{14} \mathrm{OH}^{+}$ \\
\hline methylchavicol & 149 & 0.04 & $+80 \%-30 \%$ & $<15 \%$ & $\mathrm{C}_{10} \mathrm{H}_{12} \mathrm{OH}^{+}$ \\
\hline M155 & 155 & 0.030 & $+180 \%-30 \%$ & $<30 \%$ & $\mathrm{C}_{10} \mathrm{H}_{18} \mathrm{OH}^{+}, \mathrm{C}_{9} \mathrm{H}_{14} \mathrm{O}_{2} \mathrm{H}^{+}$ \\
\hline M169 & 169 & 0.012 & $+180 \%-30 \%$ & $<50 \%$ & $\mathrm{C}_{11} \mathrm{H}_{20} \mathrm{OH}^{+}, \mathrm{C}_{10} \mathrm{H}_{16} \mathrm{O}_{2} \mathrm{H}^{+}$ \\
\hline${\mathrm{MVK}+\mathrm{MACR}^{d}}^{d}$ & 71 & 2.5 & $\pm 20 \%$ & $<5 \%$ & $\mathrm{C}_{4} \mathrm{H}_{6} \mathrm{OH}^{+}$ \\
\hline OX01 & 111 & 0.14 & $\pm 30 \%$ & $<15 \%$ & $\mathrm{C}_{8} \mathrm{H}_{14} \mathrm{H}^{+}, \mathrm{C}_{6} \mathrm{H}_{6} \mathrm{O}_{2} \mathrm{H}^{+}, \mathrm{C}_{7} \mathrm{H}_{10} \mathrm{OH}^{+}$ \\
\hline OX02 & 113 & 0.5 & $\pm 30 \%$ & $<5 \%$ & $\mathrm{C}_{8} \mathrm{H}_{16} \mathrm{H}^{+}, \mathrm{C}_{7} \mathrm{H}_{12} \mathrm{OH}^{+}, \mathrm{C}_{6} \mathrm{H}_{8} \mathrm{O}_{2} \mathrm{H}^{+}, \mathrm{C}_{5} \mathrm{H}_{4} \mathrm{O}_{3} \mathrm{H}^{+}$ \\
\hline OX03 & 141 & 0.08 & $+80 \%-30 \%$ & $<15 \%$ & $\mathrm{C}_{10} \mathrm{H}_{20} \mathrm{H}^{+}, \mathrm{C}_{9} \mathrm{H}_{16} \mathrm{OH}^{+}, \mathrm{C}_{8} \mathrm{H}_{12} \mathrm{O}_{2} \mathrm{H}^{+}, \mathrm{C}_{7} \mathrm{H}_{8} \mathrm{O}_{3} \mathrm{H}^{+}$ \\
\hline $\mathrm{OX} 04^{c}$ & 159 & 0.035 & $+180 \%-30 \%$ & $<30 \%$ & $\mathrm{C}_{12} \mathrm{H}_{14} \mathrm{H}^{+}, \mathrm{C}_{10} \mathrm{H}_{22} \mathrm{OH}^{+}, \mathrm{C}_{9} \mathrm{H}_{18} \mathrm{O}_{2} \mathrm{H}^{+}, \mathrm{C}_{8} \mathrm{H}_{14} \mathrm{O}_{3} \mathrm{H}^{+}$ \\
\hline OX05 & 163 & 0.06 & $+180 \%-30 \%$ & $<15 \%$ & $\mathrm{C}_{12} \mathrm{H}_{18} \mathrm{H}^{+}, \mathrm{C}_{11} \mathrm{H}_{14} \mathrm{OH}^{+}, \mathrm{C}_{10} \mathrm{H}_{10} \mathrm{O}_{2} \mathrm{H}^{+}, \mathrm{C}_{9} \mathrm{H}_{6} \mathrm{O}_{3} \mathrm{H}^{+}$ \\
\hline OX06 & 191 & 0.025 & $+180 \%-30 \%$ & $<30 \%$ & $\mathrm{C}_{14} \mathrm{H}_{22} \mathrm{H}^{+}, \mathrm{C}_{13} \mathrm{H}_{18} \mathrm{OH}+$ \\
\hline OX07 & 195 & 0.045 & $+180 \%-30 \%$ & $<30 \%$ & $\mathrm{C}_{14} \mathrm{H}_{26} \mathrm{H}^{+}, \mathrm{C}_{13} \mathrm{H}_{24} \mathrm{OH}^{+}, \mathrm{C}_{12} \mathrm{H}_{20} \mathrm{O}_{2} \mathrm{H}^{+}$ \\
\hline $\mathrm{OX} 08^{c}$ & 105 & 0.13 & $\pm 30 \%$ & $<15 \%$ & $\mathrm{C}_{8} \mathrm{H}_{8} \mathrm{H}^{+}$ \\
\hline $\mathrm{OX} 09^{c}$ & 123 & 0.13 & $\pm 30 \%$ & $<15 \%$ & $\mathrm{C}_{9} \mathrm{H}_{14} \mathrm{H}^{+}, \mathrm{C}_{8} \mathrm{H}_{10} \mathrm{OH}^{+} \mathrm{C}_{7} \mathrm{H}_{6} \mathrm{O}_{2} \mathrm{H}^{+}$ \\
\hline OX10 & 145 & 0.055 & $+80 \%-30 \%$ & $<15 \%$ & $\mathrm{C}_{11} \mathrm{H}_{12} \mathrm{H}^{+}, \mathrm{C}_{10} \mathrm{H}_{8} \mathrm{OH}^{+} \mathrm{C}_{8} \mathrm{H}_{16} \mathrm{O}_{2} \mathrm{H}^{+}$ \\
\hline OX11 & 173 & 0.025 & $+180 \%-30 \%$ & $<30 \%$ & $\mathrm{C}_{13} \mathrm{H}_{16} \mathrm{H}^{+}, \mathrm{C}_{12} \mathrm{H}_{12} \mathrm{OH}^{+}, \mathrm{C}_{10} \mathrm{H}_{20} \mathrm{O}_{2} \mathrm{H}^{+}, \mathrm{C}_{11} \mathrm{H}_{8} \mathrm{O}_{2} \mathrm{H}^{+}$ \\
\hline OX12 & 177 & 0.016 & $+180 \%-30 \%$ & $<30 \%$ & $\mathrm{C}_{13} \mathrm{H}_{20} \mathrm{H}^{+}, \mathrm{C}_{12} \mathrm{H}_{16} \mathrm{OH}^{+}, \mathrm{C}_{11} \mathrm{H}_{12} \mathrm{O}_{2} \mathrm{H}^{+}$ \\
\hline OX13 & 179 & 0.015 & $+180 \%-30 \%$ & $<30 \%$ & $\mathrm{C}_{13} \mathrm{H}_{22} \mathrm{H}^{+}, \mathrm{C}_{12} \mathrm{H}_{18} \mathrm{OH}^{+}, \mathrm{C}_{11} \mathrm{H}_{14} \mathrm{O}_{2} \mathrm{H}^{+}$ \\
\hline
\end{tabular}

a 2-Methyl-3-butene-2-ol;

${ }^{b}$ sum of total monoterpenes

${ }^{c}$ the diurnal course of these compounds shows features that are indicative of partitioning into the particle phase.

$d$ sum of methylvinylketone and methacrolein.

Typically 5 scans per level were used to compute average datasets on an hourly basis. Table 1 lists the $\mathrm{m} / \mathrm{z}$ monitored and the corresponding compounds. For methanol, acetaldehyde, 2-Methyl-3-butene-2-ol (MBO), acetone, total monoterpenes, and the sum of methyl vinyl ketone and methacrolein (MVK+MACR) we have used experimentally determined reaction rate constants. Gravimetrically mixed gas-standards of acetaldehyde, MBO, acetone, MVK, MACR, and several monoterpenes were automatically measured on a regular basis to cross-check the correct calculation of the concentration. The accuracy for these compounds is better than $\pm 20 \%$. For all other compounds the concentration has been computed using calculated values for the collision rate constant which should equal the reaction rate constant within $\pm 30 \%$. In addition to our automated standard additions we also measured standards of nopinone, $\beta$-carophyllene, and methylchavicol and found our system to be reliable for measuring these sort of compounds. The transmission efficiency of the mass spectrometer was regularly measured up to $\mathrm{m} / \mathrm{z}$ values of 140 . Extrapolating the transmission efficiency above this value may result in overestimation because an insufficiently tuned mass scale of the mass spectrometer and aging of the secondary electron multiplier (SEM) reduced transmission efficiency of high masses. Therefore we may have underestimated mixing ratios for compounds with molecular weights exceeding $140 \mathrm{amu}$, and accounted for this by using asymmetrical accuracy levels in Table 1.

\section{Results and discussion}

\subsection{Observations}

Figures $2 \mathrm{a}-\mathrm{d}$ shows vertical gradients and diurnal cycles for 4 compounds. To create these images we interpolated median values calculated from the 47 days for each compound, hour and height-level. We found that diurnal patterns were clearer using median rather than mean mixing ratios; however both the patterns and absolute values were very similar. 

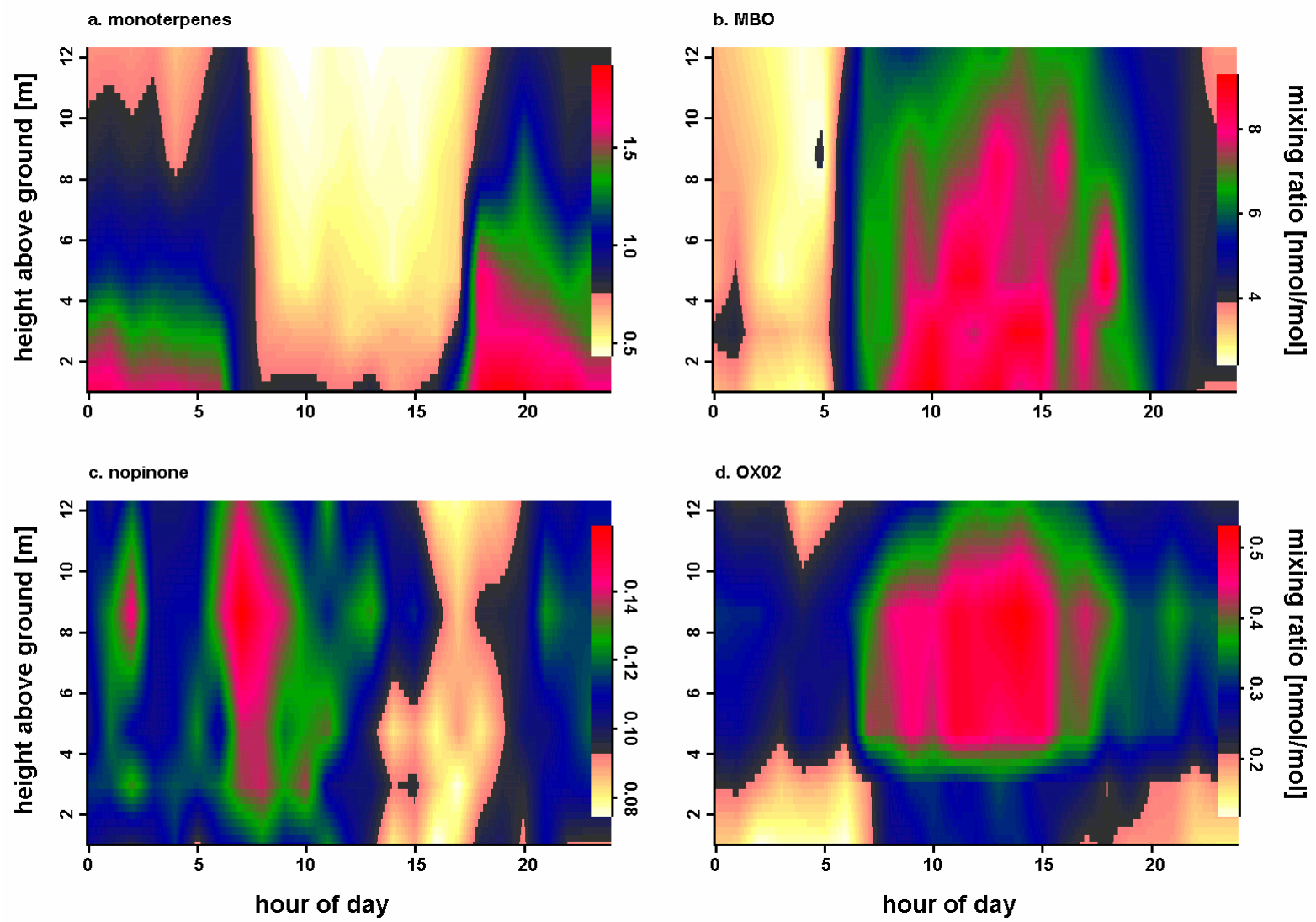

Fig. 2. Vertical gradients for individual compounds. Measurements over 47 days were averaged to produce profiles representative of summer 2003. Monoterpenes (a) and MBO (b) are examples of primary biogenic emissions. Decreasing mixing ratios during the day are indicative of heterogeneous chemistry of nopinone (c). Highest concentrations above the canopy identify OX02 (d) as an oxidation product with a strong local source.

Higher concentrations in the canopy provide a clear signature showing that terpenes (Fig. 2a) are emitted from the ecosystem. Temperature is the main driver for monoterpene emissions. The short lifetimes of terpenes (minutes to hours) result in low concentrations during the day as compared to nighttime when both oxidation and vertical mixing are slower.

MBO (Fig. 2b) is another biogenically emitted compound whose emission has been previously reported from this site (Schade et al., 2000). In contrast to monoterpenes, the emission of MBO also requires light; therefore both the mixing ratios and gradients reach minimum values at night when no emission occurs.

Nopinone (Fig. 2c) is known to be produced from the oxidation of $\beta$-pinene by $\mathrm{OH}$. The reported molar yields vary from 0.27 (Hakola et al., 1994) to 0.79 (Hatakeyama et al., 1991). Its concentration was generally highest above the trees at the $8.75 \mathrm{~m}$ level. The same trend was observed for pinonaldehyde which is the equivalent product formed from $\alpha$-pinene oxidation. Considering gas phase chemistry, increasing mixing ratios would be expected during the day since the $\mathrm{OH}$-lifetime of nopinone is about 5 times that of $\beta$-pinene (Fuentes et al., 2000) and relatively constant $\beta$-pinene concentrations were usually observed from morning through afternoon. However, nopinone concentrations were highest in the morning (09:00-10:00 PST, Pacific Standard Time, i.e. UTC- $8 \mathrm{hrs}$ ) and lowest in the afternoon (15:00-17:00 PST). Assuming yields of 0.27 and 0.79 respectively, daytime levels of $\beta$-pinene of $125 \mathrm{pmol} / \mathrm{mol}(25 \%$ of total monoterpenes), and considering gas-phase chemistry alone, nopinone mixing ratios of $160-460 \mathrm{pmol} / \mathrm{mol}$ would be expected. However daytime levels were only 85 $120 \mathrm{pmol} / \mathrm{mol}$, and therefore other loss mechanisms must exist. The decrease of nopinone from morning to afternoon is anti-correlated with increases in aerosol concentration over the same period. We conclude that the decrease of nopinone and pinonaldehyde through the day provides clear evidence of partitioning into the particle phase. This is consistent with observations by Kavouras et al. (1999), who found nopinone in both the gas and the particle phase in a forest environment.

The signal detected at mass 113 (OX02, Fig. 2d) is representative of a whole class of compounds. These compounds 


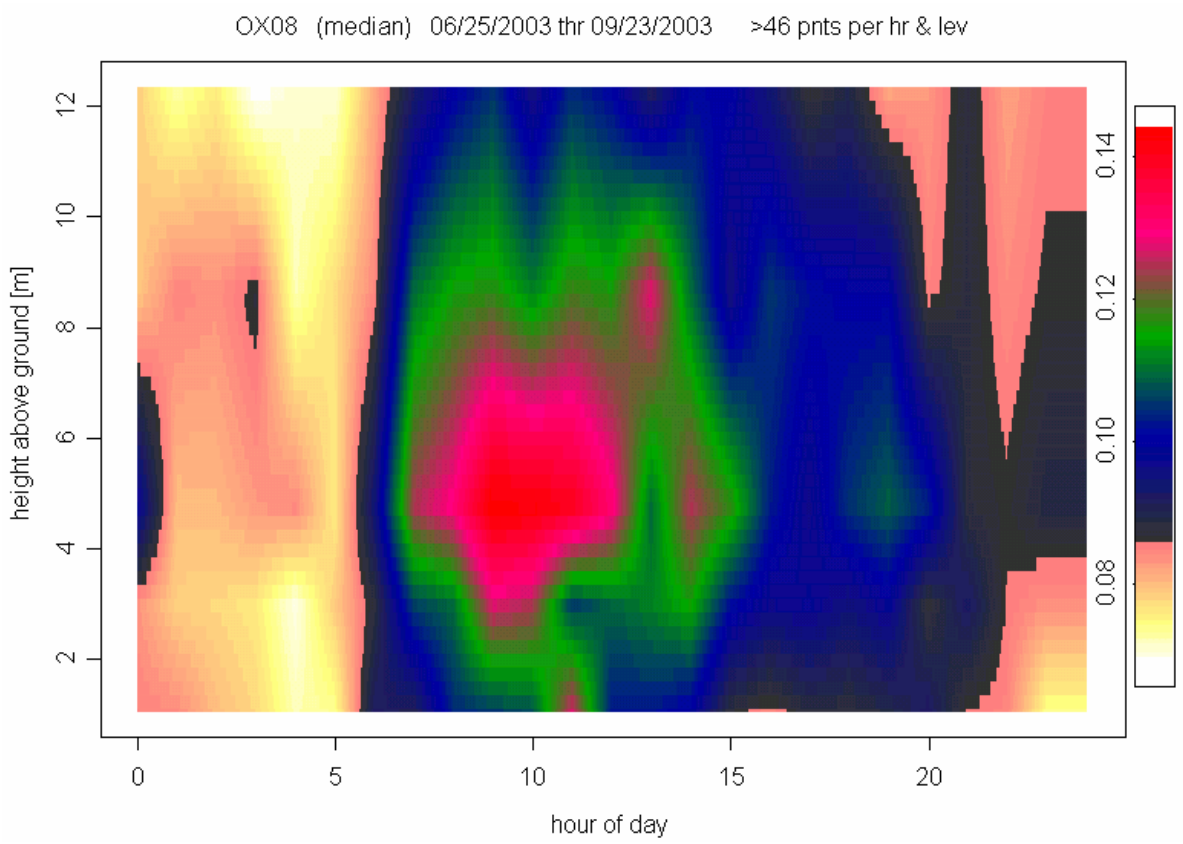

Fig. 3. OX08 is an example oxidation product indicating heterogeneous chemistry: While rising ozone levels and increasing solar radiation increase its production, mixing ratios decrease after reaching a maximum at 10:00 PST. In analogy to observations of nopinone mixing ratios we infer that partitioning into the particle phase is a likely cause for the unexpected decrease from morning to afternoon.

behave similarly, and have so far only been identified by their mass to charge ratios (see Table 1). Their diurnal and vertical profiles typically share the following characteristics: (i) higher concentration above than within the canopy; (ii) significantly lower concentration at both the top and the bottom levels; and (iii) nighttime concentrations significantly lower than daytime concentrations. Because the concentration maximum is spatially separated from any primary emission source, these compounds must be oxidation products of primary biogenic compounds whose emissions are highest during daytime. Lower concentrations at the bottom level suggest efficient dry deposition of these compounds. However, their vertical profiles are not consistent with the profiles observed for primary emissions such as MBO and monoterpenes even when considering a balance between soil deposition and direct biogenic emission: the spatial separation of the region of highest concentrations (e.g. 5-9 m for OX02, Fig. 2d) from primary emission sources (average tree height $<4.9 \mathrm{~m}, 80 \%$ of the trees below $6.4 \mathrm{~m}$ ) is a significant piece of evidence that needs to be explained when considering their source. We do not think it is possible to explain the observed profile without assuming these compounds are oxidation products. However, possible primary emission cannot be completely ruled out for some of the "OX"-products listed in Table 1 because their maximum concentration was not clearly above the forest canopy which is the case for OX01, OX08 (see Fig. 3), OX09, and OX11-OX13.
In addition, another strong piece of evidence for the OXproducts not being primary emission is provided by enclosure experiments that were also performed in summer 2003. Branches of the most abundant plant species were enclosed in a Teflon chamber and the chamber air was flushed completely approximately once per minute. While mixing ratios of primary emissions (e.g. methanol, monoterpenes, sesquiterpenes, $\mathrm{MBO}$, etc.) were dramatically enhanced in the chamber to multiple times the concentration in ambient air, mixing ratios of oxidation products like OX02 did not exhibit significant increases inside the chamber.

During night the production of this type of compounds continues, however, at a much slower rate; for comparison consider that the emission rate of monoterpenes during night is reduced too; nevertheless concentrations are much higher at night mainly due to reduced vertical mixing of the surface layer. The concentration of OX02 slightly increases during the day; a feature which is not shared by all compounds of this group. E.g. the mixing ratio of OX08 (Fig. 3) at 4$8 \mathrm{~m}$ continuously decreases after 11:00 or 12:00 PST while OX02 is increasing. Similar to our argument for nopinone and pinonaldehyde, we infer that some of the oxidation products (identified in Table 1) efficiently partition into the particle phase.

Potential artifacts due to ozone or water in our inlet system must be considered. To make sure the sample flow path would be the same for each sampling height, we designed all five gradient inlets identically (same flow rate at all times, 
a

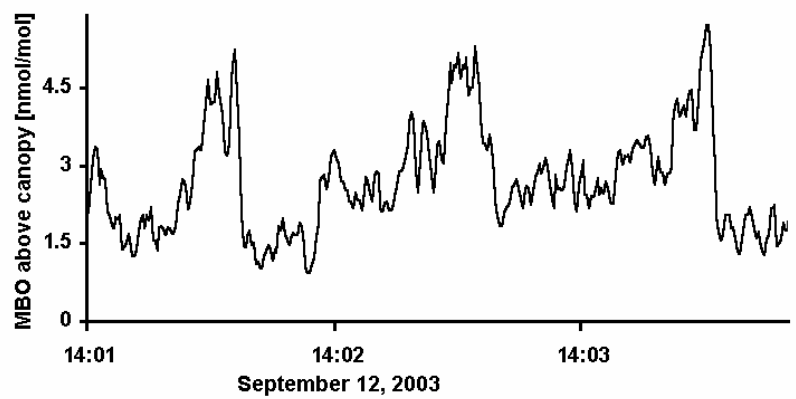

b

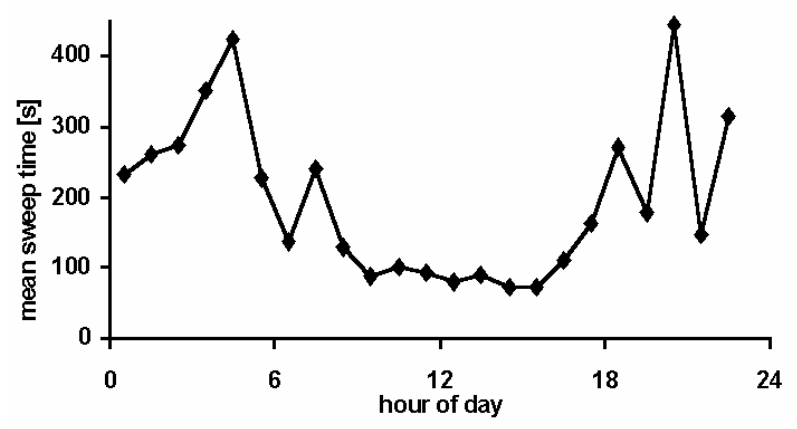

Fig. 4. (a) Ramp structures are regularly observed in high time resolution measurements of MBO. Gusts caused by wind shear periodically sweep the forest canopy and are observed in the MBO data as sharp decreases in concentration $(\sim 14: 01: 40,14: 02: 40$, and 14:03:40). (b) Diurnal cycle of the median sweep time in summer 2003. During daytime the median sweep time is a reasonable measure for the turnover time of air in the canopy.

same materials, filters, valves and length of tubing). During daytime ozone vertical gradients were small (less than 10\%). The vertical gradients of water concentration were similar to those of primary emissions (e.g. monoterpenes), with highest concentrations at the bottom level and sequentially lower concentrations at higher levels. The vertical gradients of oxidation products (OX01-OX13, Table 1) were not correlated with water or ozone, indicating there are not artifacts in our profiles from either of these gases.

\subsection{Emission and production}

The discovery of high concentrations and large gradients of oxidation products in the forest canopy are important findings; they provide firm evidence of unmeasured emission of very reactive biogenic volatile organic compounds. In the following discussion we estimate production rates for the oxidation products, and we also assess emission rates of the underlying VR-BVOCs that are needed to explain the observed oxidation products.

In order to calculate an emission or production rate from a gradient profile, we used a simplified surface renewal model
(Paw U et al., 1995). The surface renewal method, specifically based on the coherent structure/ramp repetition duration and amplitude of ramp patterns for any scalar above a rough surface, has been tested numerous times, e.g. Spano et al. (2000), Zapata and Martinez-Cob (2002).

If chemical or physical loss is negligible on time scales of air mixing through the canopy the production rate $\left(P_{V O C}\right)$ of a trace gas can be calculated according to

$P_{V O C}=\frac{E A_{V O C}}{t_{m i x}}$,

where $t_{m i x}$ is the mean mixing time of the air in the gradient profile and $E A_{V O C}$ is the excess amount of the trace gas observed within the profile. The excess amount per unit of surface area is calculated according to

$E A_{V O C}=\left(\int_{0}^{h}[V O C] d z-h[V O C]_{B}\right)$,

where $h$ is the cut off height above the canopy (highest measurement level, $12.5 \mathrm{~m}$ ); [VOC] is the concentration of the trace gas at height $z$; and $[\mathrm{VOC}]_{B}$ is the background concentration measured at $12.5 \mathrm{~m}$. However, some of the oxidation products OX01-OX13 were still significantly above the local background at $12.5 \mathrm{~m}$ (see Fig. 2d); in these cases the $1.1 \mathrm{~m}$ level has been used as local background whenever the concentration was lower than at the $12.5 \mathrm{~m}$ level. This simple model is a reasonable approach for calculating production rates from vertical gradient data as presented here which are averaged over many similar days.

We assumed that $t_{m i x}$ should equal the average turnover time (or interval between sweeps) of air within the canopy. Figure 4a shows the evolution of MBO concentration over 3 min during which typical ramp structures have been observed. Ramp structures occur over rough surfaces for any scalar which is exchanged or locally produced. In the case of compounds emitted from forests a ramp feature is characterized by a gradual rise in concentration followed by a relatively sharp drop. These structures are associated with turbulent coherent structures which scale with wind shear at the canopy top (Chen and Blackwelder, 1978); the wind shear causes updrafts at lower heights which, in return, causes instability unwinding in periodic gusts or sweeps. In many cases this is the prevailing mechanism for gas exchange in the canopy. Paw U et al. (1993) found that the average sweep time is a function of the canopy shear scale (average wind speed at canopy height divided by canopy height). We assumed $t_{m i x}$ could be equated to the median value of the interval between scalar ramps, obtained using structure function analysis (Snyder et al., 1996) of the turbulent traces of temperature. The median ramp repetition intervals of approximately 1.5 minutes during the day, and 3-7 $\mathrm{min}$ at night (calculated using structure function analysis, Fig. 4b) were generally consistent with estimates of the repetition interval 
Table 2. Production/emission, lifetime, and reactivity of primary emissions and oxidation products.

\begin{tabular}{|c|c|c|c|c|}
\hline name & $\begin{array}{c}\text { production } \\
{\left[\mu \mathrm{mol} \mathrm{m}^{-2} \mathrm{~h}^{-1}\right]}\end{array}$ & $\begin{array}{l}\text { previously reported emission for this } \\
\text { site by GC-REA }\left[\mu \mathrm{mol} \mathrm{m}^{-2} \mathrm{~h}^{-1}\right]\end{array}$ & lifetime $^{c}$ & {$\left[10^{6}{\left.\text { reactions } \mathrm{cm}^{-3} \mathrm{~s}^{-1}\right]}^{\text {reactivity }}\right.$} \\
\hline Monoterpenes & 2.2 & $4.1^{a}$ & $0.3-0.8^{e} \mathrm{hrs}$ & $4-9$ \\
\hline MBO & 29 & $25^{b}$ & $0.3-0.8 \mathrm{hrs}$ & $60-150$ \\
\hline Nopinone & 0.08 & & $1.3-3.3 \mathrm{hrs}$ & $0.2-0.6$ \\
\hline OX01 & 0.59 & & & $30-155$ \\
\hline OX02 & 2.6 & & & $135-675$ \\
\hline OX03 & 0.40 & & & $20-105$ \\
\hline OX04 & 0.28 & & & $15-75$ \\
\hline OX05 & 0.61 & & & $30-160$ \\
\hline OX06 & 0.25 & & & $15-65$ \\
\hline OX07 & 0.38 & & & $20-100$ \\
\hline OX08 & 0.37 & & & $20-95$ \\
\hline OX09 & 0.36 & & & $20-95$ \\
\hline OX10 & 0.34 & & & 20-90 \\
\hline OX11 & 0.17 & & & $10-45$ \\
\hline OX12 & 0.12 & & & $5-30$ \\
\hline OX13 & 0.11 & & & $5-30$ \\
\hline sum OX & 6.6 & & & $345-1720$ \\
\hline
\end{tabular}

${ }^{a}$ Schade et al. (1999), daytime average of the sum of $\Delta$-3-carene, $\alpha$-pinene and limonene, July to October 1998.

${ }^{b}$ Schade and Goldstein (2001), daytime averages, summer 1999.

${ }^{c}$ With rate constants at $298 \mathrm{~K}$ (see Fuentes et al. (2000); Atkinson (2000) and references therein) and daytime OH concentrations of 5$13 \times 10^{6}$ molecules per $\mathrm{cm}^{3}$ (Dreyfus et al., 2002).

${ }^{d}$ In the case of OX01-OX13 reactivity refers to the reactivity of the precursor compounds. The range reflects oxidation product yields of $10-50 \%$.

$e$ assuming $\alpha$-pinene, $\beta$-pinene and 3-carene at a ratio of 7:9:4; these compounds constitute over $60 \%$ of total monoterpenes (Lee et al., 2004).

of turbulent coherent structures using estimated wind shear and Paw U et al. (1993), thus lending confidence to these estimates from two independent techniques.

To test our approach (Eqs. 1 and 2) we calculated emissions of total monoterpenes and $\mathrm{MBO}$, for comparison with eddy-flux measurements. During daytime when most emission occurs we found reasonable agreement of $\pm 30 \%$ between the two methods. The fluxes of total monoterpenes and MBO obtained by the two independent methods are in agreement with previous measurements at the site (Schade and Goldstein, 2001; Schade et al., 2000; Schade et al., 1999). These comparisons show that our adapted surface renewal approach yields reliable results, however, it remains disputable whether the accuracy is $+/-30 \%$ (our estimate) or slightly higher or lower.

We then used averages of the whole 47-day dataset (10:00-16:00 PST) to calculate production rates for the observed oxidation products (Table 2). In order to account for the potential underestimation of compounds with masses above $140 \mathrm{amu}$ we adjusted the mixing ratios according to the range of accuracy given in Table 1: e.g. a mixing ratio of $60 \mathrm{pmol} / \mathrm{mol}$ was measured for OX10 (145 amu); in Table 1 we stated a accuracy of $+80 \%$ and $-30 \%$; so we would use a mixing ratio of $75 \mathrm{pmol} / \mathrm{mol}$ (i.e. $[60 \times 1.8+60 \times 0.7] / 2$ ) to calculate the production according to Eqs. (1) and (2).
The production for the individual oxidation products ranges from 0.1 to $2.6 \mu \mathrm{mol} \mathrm{m}{ }^{-2} \mathrm{~h}^{-1}$; together they sum up to $6.6 \mu \mathrm{mol} \mathrm{m}^{-2} \mathrm{~h}^{-1}$. The actual production rate for these oxidation products may be considerably higher if their lifetimes are in the range of $t_{\text {mix }}$. Nevertheless, the value of $6.6 \mu \mathrm{mol} \mathrm{m}^{-2} \mathrm{~h}^{-1}$ is at least 3 times the emission of total monoterpenes measured above the canopy; the underlying VR-BVOC emission must be at least that high. It is, however, unrealistic to assume that all $(100 \%)$ of the VR-BVOC emission is converted into the measured oxidation products. As discussed above the oxidation products are deposited to the soil and they may be lost onto particles; furthermore, many reaction pathways may yield products that could not be detected with our current instrumentation. We assume a more realistic photochemical production yield would be $10-50 \%$ for the measured oxidation products. Given this yield range, the underlying VR-BVOC emission must be 13$66 \mu \mathrm{mol} \mathrm{m}^{-2} \mathrm{~h}^{-1}$, which on a molar basis is 6-30 times the emission of total monoterpenes measured above the canopy. Presumably the VR-BVOCs are terpenoid compounds and therefore contain at least 10 carbon atoms per molecule. Given that average daytime $\mathrm{CO}_{2}$ flux was $28 \mathrm{mmol} \mathrm{m}^{-2} \mathrm{~h}^{-1}$, VR-BVOC emission would be $0.5-2.4 \%$ of the net $\mathrm{C}$ uptake as $\mathrm{CO}_{2}$. On a carbon basis, the VR-BVOCs exceed the emission of $\mathrm{MBO}\left(0.5 \%\right.$ of net uptake of $\left.\mathrm{CO}_{2}\right)$ and constitute the largest class of biogenic emissions at our site. 


\subsection{Reactivity}

Using typical mixing ratios given in Table 1 and Lamanna and Goldstein (1999), and lifetimes based on estimated daytime $\mathrm{OH}$ concentrations of $0.5-1.3 \times 10^{7}$ molecules $\mathrm{cm}^{-3}$ (Dreyfus et al., 2002) we calculated the total reactivity of commonly measured compounds to be of order 8.5$22 \times 10^{7}$ reactions $\mathrm{cm}^{-3} \mathrm{~s}^{-1}$; with $\mathrm{MBO}$, isoprene+products, monoterpenes, acetaldehyde, and methanol constituting about $98 \%$ of this reactivity (see also Table 2). The reactivity of the VR-BVOCs must equal the production rate of the oxidation products OX01-OX13 divided by the yield. We calculated their area-specific reactivity and divided by the canopy height of $6.5 \mathrm{~m}$ to convert it to a volumetric basis. Conservatively assuming a yield of $10-50 \%$, the reactivity of the VR-BVOCs is $3.5-17 \times 10^{8}$ reactions $\mathrm{cm}^{-3} \mathrm{~s}^{-1}$, which is about 2-10 times the reactivity of the sum of all other compounds. Kurpius and Goldstein (2003) inferred that during summer days $\sim 20 \mu \mathrm{mol} \mathrm{m}^{-2} \mathrm{~h}^{-1}$ of the total ozone flux into the ecosystem was due to chemical loss in the forest canopy. To maintain this flux a reactivity of $5.25 \times 10^{8}$ reactions $\mathrm{cm}^{-3} \mathrm{~s}^{-1}$ is needed throughout the canopy, which is consistent with our results.

Ozone chemistry must play an important role in the formation of the observed oxidation products. Typical levels of $50-100 \mathrm{nmol} / \mathrm{mol} \mathrm{O}_{3}$ during the day result in atmospheric lifetimes of many reactive terpenes of less than one minute; some of these have been qualitatively identified as biogenic emission from local plant species (Goldstein et al., 2004). Conversely, estimated $\mathrm{OH}$ levels of $0.5-$ $1.3 \times 10^{7}$ molecules $\mathrm{cm}^{-3}$ (Dreyfus et al., 2002) result in lifetimes no shorter than 5 minutes for the most reactive compounds. Although we argue that estimated $\mathrm{OH}$ levels above the canopy are too low to cause observed levels of oxidation products, $\mathrm{OH}$-reactions certainly contribute to the short lifetime of unmeasured precursor compounds. Furthermore, according to (Paulson et al., 1999) reactions of ozone with alkenes produce $\mathrm{OH}$-radicals; and in this way $\mathrm{OH}$ reactions can play a more significant role by amplifying the ozone initiated degradation process.

\section{Conclusions}

Emission of VR-BVOC has been previously reported: $\mathrm{Ci}-$ ccioli et al. (1999) observed $\beta$-caryophyllene emissions in plant enclosures which were not observable above the forest canopy presumably because of their short lifetime with respect to reaction with ozone. The novelty we are reporting here is the magnitude of VR-BVOC emission. Substantial VR-BVOC emissions have been postulated due to measurements that were otherwise hard to explain. Faloona et al. (2001) observed elevated $\mathrm{OH}$ concentrations at night correlated with $\mathrm{O}_{3}$ mixing ratios in a northern Michigan mixed deciduous forest in 1998, and suggested the $\mathrm{OH}$ was likely produced from reactions of $\mathrm{O}_{3}$ with unmeasured terpenes. O'Dowd et al. (2002) suggested new particle growth measured in a boreal forest in Finland in 2000 occurred from condensation or coagulation of terpene oxidation products. Most recently, Di Carlo et al. (2004) showed that the total $\mathrm{OH}$ reactivity above a northern Michigan deciduous forest in summer 2000 exceeded what could be explained by known VOCs, and the excess increased exponentially with temperature inferring that unknown biogenic terpenes were likely responsible. In light of our observations we infer that in each of these cases VR-BVOC could indeed be responsible. These observations suggest that our findings will hold for other ecosystems, thus global terpene emission and secondary organic aerosol formation likely is larger than previously assumed.

Acknowledgements. We want to thank all reviewers for their time and constructive comments. We were pleased at the amount of careful consideration and discussion that was generated from our novel observations and interpretations (see http://overview.sref.org/ 1680-7375/acpd/2004-4-5345).

This research was funded by the National Science Foundation Atmospheric Chemistry Program (award ATM-0119510), the California Air Resources Board (ARB contract numbers 98-328 and 00-732), and the University of California Agricultural Experiment Station. We thank M. McKay, B. Heald, D. Rambeau, and the Blodgett Forest crew for operational support, and Sierra Pacific Industries for use of their land and assistance in field site operations. We also thank R. Cohen, P. Crutzen, and I. Faloona for insightful comments on drafts of this article. Partial support for K. Paw U came from the Western Regional Center (WESTGEC) of the National Institute for Global Environmental Change (NIGEC) through the Environmental Sciences Division, PER program, of the U.S. Department of Energy (DOE) (Cooperative Agreement No. DE-FC03-90ER61010). Any opinions, findings and conclusions or recommendations expressed herein are those of the authors and do not necessarily reflect the view of the DOE.

Edited by: A. B. Guenther

\section{References}

Atkinson, R.: Atmospheric chemistry of VOCs and $\mathrm{NO}_{\mathrm{x}}$, Atmos. Environ., 34 (12-14), 2063-2101, 2000.

Bauer, M. R., Hultman, N. E., Panek, J. A., and Goldstein, A. H.: Ozone deposition to a ponderosa pine plantation in the Sierra Nevada Mountains (CA): A comparison of two different climatic years, J. Geophys. Res., 105 (D17), 22 123-22 136, 2000.

Chen, C. H. P. and Blackwelder, R. F.: Large-Scale Motion in a Turbulent Boundary-Layer - Study Using Temperature Contamination, J. Fluid Mech., 89 (NOV), 1-31, 1978.

Ciccioli, P., Brancaleoni, E., Frattoni, M., Di Palo, V., Valentini, R., Tirone, G., Seufert, G., Bertin, N., Hansen, U., Csiky, O., Lenz, R., and Sharma, M.: Emission of reactive terpene compounds from orange orchards and their removal by within-canopy processes, J. Geophys. Res., 104 (D7), 8077-8094, 1999.

Di Carlo, P., Brune, W. H., Martinez, M., Harder, H., Lesher, R., Ren, X., Thornberry, T., Carroll, M. A., Young, V., Shepson, P. 
B., Riemer, D., Apel, E., and Campbell, C.: Missing OH Reactivity in a Forest: Evidence for Unknown Reactive Biogenic VOCs, Science, 304, 722-725, 2004.

Dillon, M. B., Lamanna, M. S., Schade, G. W., Goldstein, A. H., and Cohen, R. C.: Chemical evolution of the Sacramento urban plume: Transport and oxidation, J. Geophys. Res., 107 (D5-6), doi:10.1029/2001JD000969, 2002.

Dreyfus, G. B., Schade, G. W., and Goldstein, A. H.: Observational constraints on the contribution of isoprene oxidation to ozone production on the western slope of the Sierra Nevada, California, J. Geophys. Res., 107 (D19), doi:10.1029/2001JD001490, 2002.

Faloona, I., Tan, D., Brune, W., Hurst, J., Barket, D., Couch, T. L., Shepson, P., Apel, E., Riemer, D., Thornberry, T., Carroll, M. A., Sillman, S., Keeler, G. J., Sagady, J., Hooper, D., and Paterson, K.: Nighttime observations of anomalously high levels of hydroxyl radicals above a deciduous forest canopy, J. Geophys. Res., 106 (D20), 24 315-24 333, 2001.

Fuentes, J. D., Lerdau, M., Atkinson, R., Baldocchi, D., Bottenheim, J. W., Ciccioli, P., Lamb, B., Geron, C., Gu, L., Guenther, A., Sharkey, T. D., and Stockwell, W.: Biogenic hydrocarbons in the atmospheric boundary layer: A review, B. Am. Meteorl. Soc., 81 (7), 1537-1575, 2000.

Goldstein, A. H., Hultman, N. E., Fracheboud, J. M., Bauer, M. R., Panek, J. A., Xu, M., Qi, Y., Guenther, A. B., and Baugh, W.: Effects of climate variability on the carbon dioxide, water, and sensible heat fluxes above a ponderosa pine plantation in the Sierra Nevada (CA), Agr. Forest Meteorol., 101 (2-3), 113-129, 2000.

Goldstein, A. H., McKay, M., Kurpius, M. R., Schade, G. W., Lee, A., Holzinger, R., and Rasmussen, R.: Forest thinning experiment confirms ozone deposition to forest canopy is dominated by reaction with biogenic VOCs, Geophys. Res. Lett., 31 (L22106), doi:10.1029/2004GL021259, 2004.

Hakola, H., Arey, J., Aschmann, S. M., and Atkinson, R.: Product Formation from the Gas-Phase Reactions of Oh Radicals and O3 with a Series of Monoterpenes, J. Atmos. Chem., 18 (1), 75-102, 1994.

Hatakeyama, S., Izumi, K., Fukuyama, T., Akimoto, H., and Washida, N.: Reactions of Oh with Alpha-Pinene and BetaPinene in Air - Estimate of Global Co Production from the Atmospheric Oxidation of Terpenes, J. Geophys. Res., 96 (D1), 947958, 1991.

Kavouras, I. G., Mihalopoulos, N., and Stephanou, E. G.: Formation and gas/particle partitioning of monoterpenes photooxidation products over forests, Geophys. Res. Lett., 26 (1), 5558, 1999.

Kurpius, M. R. and Goldstein, A. H.: Gas-phase chemistry dominates O-3 loss to a forest, implying a source of aerosols and hydroxyl radicals to the atmosphere, Geophys. Res. Lett., 30 (7), doi:10.1029/2002GL016785, 2003.
Lamanna, M. S. and Goldstein, A. H.: In situ measurements of C2-C-10 volatile organic compounds above a Sierra Nevada ponderosa pine plantation, J. Geophys. Res., 104 (D17), $21247-$ $21262,1999$.

Lee, A., Schade, G. W., Holzinger, R., and Goldstein, A. H.: A comparison of new measurements of total monoterpene flux with improved measurements of speciated monoterpene flux, Atmos. Chem. Phys. Discuss., 4, 7819-7835, 2004, SRef-ID: 1680-7375/acpd/2004-4-7819.

Lindinger, W., Hansel, A., and Jordan, A.: On-line monitoring of volatile organic compounds at pptv levels by means of protontransfer-reaction mass spectrometry (PTR-MS) - Medical applications, food control and environmental research, Int. J. Mass Spectrom., 173 (3), 191-241, 1998.

O’Dowd, C. D., Aalto, P., Hameri, K., Kulmala, M., and Hoffmann, T.: Aerosol formation - Atmospheric particles from organic vapours, Nature, 416 (6880): 497-498, 2002.

Paulson, S. E., Chung, M. Y., and Hasson, A. S.: OH radical formation from the gas-phase reaction of ozone with terminal alkenes and the relationship between structure and mechanism, J. Phys. Chem. A, 103 (41), 8125-8138, 1999.

Paw U, K. T., Brunet, Y., Collineau, S., Shaw, R. H., Maitani, T., Qui, J., and Hipps, L.: Corrigendum: On Coherent Structures in Turbulence above and within Agricultural Plant Canopies, Agr. Forest Meteorol., 63 (1-2), 127-127, 1993.

Paw U, K. T., Qiu, J., Sun, H. B., Watanabe, T., and Brunet, Y.: Surface Renewal Analysis - a New Method to Obtain Scalar Fluxes, Agr. Forest Meteorol., 74 (1-2), 119-137, 1995.

Schade, G. W., and Goldstein, A. H.: Fluxes of oxygenated volatile organic compounds from a ponderosa pine plantation, J. Geophys. Res., 106 (D3), 3111-3123, 2001.

Schade, G. W. and Goldstein, A. H.: Increase of monoterpene emissions from a pine plantation as a result of mechanical disturbances, Geophys. Res. Lett., 30 (7), doi:10.1029/2002GL016138, 2003.

Schade, G. W., Goldstein, A. H., Gray, D. W., and Lerdau, M. T.: Canopy and leaf level 2-methyl-3-buten-2-ol fluxes from a ponderosa pine plantation, Atmos. Environ., 34 (21), 3535-3544, 2000.

Schade, G. W., Goldstein, A. H., and Lamanna, M. S.: Are monoterpene emissions influenced by humidity?, Geophys. Res. Lett., 26 (14), 2187-2190, 1999.

Snyder, R. L., Spano, D., and Paw U, K. T.: Surface renewal analysis for sensible and latent heat flux density, Bound.-Lay. Meteorol., 77 (3-4), 249-266, 1996.

Spano, D., Snyder, R. L., Duce, P., and Paw U, K. T.: Estimating sensible and latent heat flux densities from grapevine canopies using surface renewal, Agr. Forest Meteorol., 104 (3), 171-183, 2000.

Zapata, N. and Martinez-Cob, A.: Evaluation of the surface renewal method to estimate wheat evapotranspiration, Agr. Water Manage., 55 (2), 141-157, 2002. 